\title{
Cerebral arterial occlusion and intracranial venous thrombosis in a woman taking
} oral contraceptives

\author{
F. MONTÓN \\ M.D. \\ F. QUINTANA \\ M.D.
}

\author{
M. REBOLLO \\ M.D. \\ J. BERCIANO \\ M.D.
}

Departments of Medicine (Section of Neurology) and Radiology (Section of Neuroradiology), CMN Marqués de Valdecilla, Faculty of Medicine, Santander, Spain

\begin{abstract}
Summary
Occlusion of the middle cerebral artery and thrombosis of the superior sagittal sinus are reported in a 30 year-old woman taking oral contraceptives $(O C)$. The coexistence of arterial and venous cerebral pathology as a complication of $\mathrm{OC}$ use has only been previously reported in one case. The pathogenesis of this rare association is briefly discussed.
\end{abstract}

KEY WORDS: hemiparesis, stroke, papilloedema.

\section{Introduction}

The risk of ischaemic stroke has consistently been found to be increased among current users of oral contraceptives (OC) (Collaborative group for the Study of Stroke in Young Women, 1973 and 1975). In addition, intracranial venous thrombosis has also been associated with the use of OC (Rousseaux et al., 1977; Navarro et al., 1978). However, the simultaneous occurrence of both complications in patients using $\mathrm{OC}$ has been reported in only one previous case (Walsh et al., 1965). Here we describe a middle cerebral artery occlusion followed by superior sagittal sinus thrombosis in a young woman who had been taking OC.

\section{Case report}

This 30-year-old woman had been taking OC (Eugynon®: norgestrel 0.5 mg; ethinyloestradiol 0.05 $\mathrm{mg}$ ) for 4 years for contraceptive purposes. She developed a headache and left hemiparesis over a period of $2 \mathrm{hr}$. On admission, in June 1980, she had left hemiplegia, hemihypoesthesia and homonymous hemianopsia. Her blood pressure was $120 / 70 \mathrm{~mm}$ $\mathrm{Hg}$. The next day a right carotid angiogram showed a

Correspondence: José Berciano, MD Sección de Neurología, CMN Marqués de Valdecilla, Santander, Spain. complete occlusion of the middle cerebral artery at its origin, the venous phase being normal (Fig. la \& b). An electroencephalogram (EEG) revealed focal low frequency delta activity in the right frontotemporal i region, with preservation of alpha rhythm posteriorly $\mathscr{\sigma}$ and in the left hemisphere. Routine haematological 웅 and biochemical screening examinations were unre- markable except for a slightly raised blood choles- $\overleftarrow{c}$ terol, $332 \mathrm{mg} / 100 \mathrm{ml}$ (normal up to $250 \mathrm{mg} / 100 \mathrm{ml}$ ) and triglycerides $237 \mathrm{mg} / 100 \mathrm{ml}$ (normal up to $\vec{\theta}$ $150-160 \mathrm{mg} / 100 \mathrm{ml}$ ). Serological studies for system 10 lupus erythematosus and syphilis, coagulation profife including antithrombin III level, electrocardiogram. and cardiological study, cerebrospinal fluid (CSF) examination and chest $\mathrm{X}$-ray were all normal.

Two days after admission, the headache worsened, with nausea and vomiting. Intravenous dexametha- $\triangle$ sone $4 \mathrm{mg}$ every $6 \mathrm{hr}$ was commenced. Her clinical $\overrightarrow{\vec{B}}$ condition improved rapidly over the next $72 \mathrm{hr}$, until $\stackrel{3}{3}$ only a slight left hemiparesis remained. Dexametha- $\bar{P}$ sone treatment was tapered off 7 days later. On the 20th day of hospitalization, a severe, persistent rightsided headache began, accompanied by profuse 3 vomiting. On examination, there was papilloedema, neck stiffness and an increased left hemiparesis. On the EEG, together with the focal delta activity in the 8 right frontotemporal region, there was now a diffuse slowing of the basic rhythms. A computerized tomo- 을 graphy (CT) scan showed a well-defined infarct hypodensity involving the right anterior capsule- 음. basal ganglia region with enlargement of the right frontal horn; signs of superior sagittal sinus thrombo- $\odot$ sis (Lee and Rao, 1983) were not observed. A left $N$ carotid angiogram disclosed slowing of the circula- N tion and occlusion of almost the entire superior 0 sagittal sinus (Fig. 1c and 2). Treatment with dexamethasone was renewed for 1 month. The patient improved rapidly over the course of the next $3 \stackrel{\circ}{\rightarrow}$ weeks. Cholesterol and triglyceride levels were nor- $T$ mal on repeated testing. Two years later, she was 

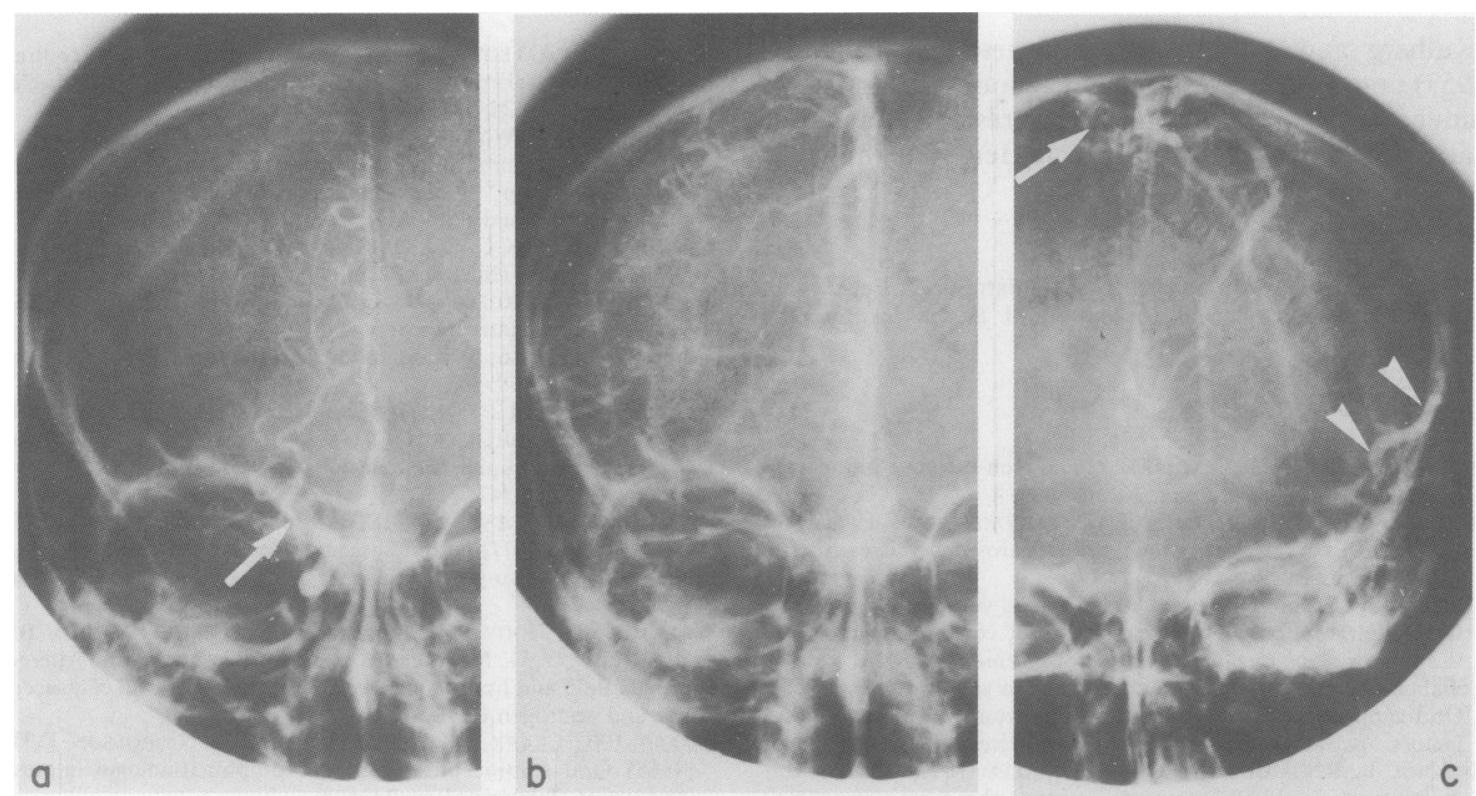

Fig. 1. (a) Complete occlusion of the right middle cerebral artery at its origin (arrow), with normal venogram. (b) Left carotid angiogram obtained during venous phase. (c) Showing non-opacification of superior sagital sinus (arrow) and considerable drainage via veins of Labbé (arrowheads).

asymptomatic and physical examination revealed only a slight weakness of the left side.

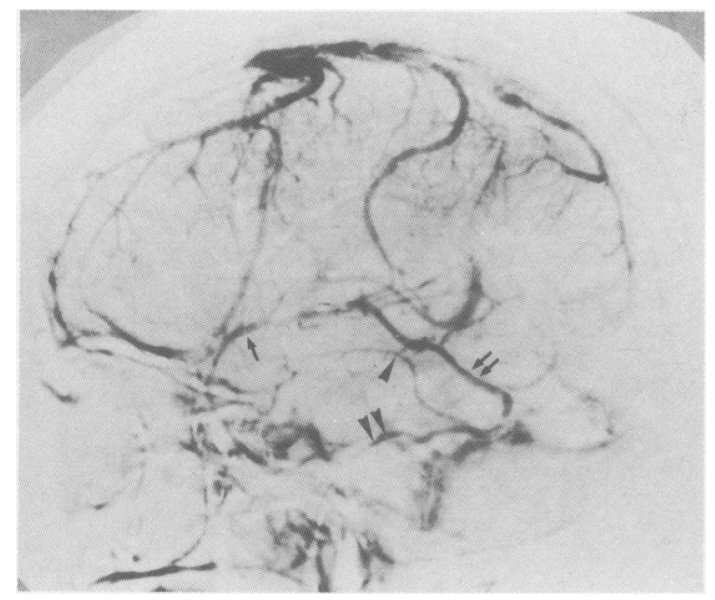

FIG. 2. Lateral view of left carotid angiogram, venous phase. Note nonopacification of superior sagital sinus. There is drainage via internal cerebral veins, sylvian vein (arrow), vein of Labbé (double arrow), temporo-basal vein (arrowhead) and superior petrosal sinus (double arrowhead).

\section{Discussion}

The clinical course of our patient was in two phases. The initial clinical manifestations are entirely compatible with the occlusion of the middle cerebral artery and the capsular infarct, demonstrated in the right carotid angiogram and CT scan respectively. The signs and symptoms as well as the electroencephalogram anomalies in both hemispheres which had developed 3 weeks later correlate well with the saggital sinus thrombosis on the left carotid angiogram (Kalbag and Woolf, 1972). The only risk factors of either arterial or venous cerebrovascular disease were the use of $O C$ and the raised levels of cholesterol and triglycerides, such as those described during OC use (Wallace et al., 1979; Oster et al., 1982). Other possible aetiologies considered in the differential diagnosis of cerebral infarction in young adults (Hart and Miller, 1983) and intracranial phlebothrombosis (Estanol et al., 1979) could reasonably be excluded in our patient.

The association of intracranial arterial and venous thrombosis in women OC users, as in the case we report here, has been previously described only in Case 1 of the series of Walsh et al. (1965). In their patient, the arteriogram showed an almost complete obstruction of the left carotid artery. On postmortem examination there was evidence of obstruction of both internal carotid arteries and venous thromboses were present in the left ophthalmic vein, all of the dural sinuses and the cerebral cortical veins. It remains to be clarified whether this association is due to the development of intracranial phlebothrombosis as a complication of cerebral arterial occlusion 
(Kalberg and Woolf., 1972; Barnett and Hyland, 1953) or to systemic arterial and venous vasculopathy induced by OC (Basdevant, Lignières and MauvaisJarvis, 1980; Irey, McAllister and Henry, 1978).

\section{Acknowledgments}

The authors are very grateful to Miss Marta de la Fuente for typing the manuscript and to Mrs Carol Elsden for English translation.

\section{References}

BARNETT, H.J.M. \& HYLAND, H.H. (1953) Non-infective intracranial venous thrombosis. Brain, 76, 36.

Basdevant, A., De Lignieres, B. \& Mauvais-Jarvis, P. (1980) Effects des contraceptifs oraux sur la paroi des vaisseaux. La Nouvelle Presse Médicale, 9, 519.

Collaborative group for the study of stroke in young women (1973) Oral contraception and increased risk of cerebral ischemia or thrombosis. New England Journal of Medicine, 288, 871.

Collaborative group for the study of stroke in young women (1975) Oral contraceptives and stroke in young women. Associated risk factors. Journal of the American Medical Association, 231, 718.

Estanol, B., RodriQuez, A., Conte, G., Aleman, J.M., Loyo, M. \& PizzuTo, J. (1979) Intracranial venous thrombosis in young women. Stroke, 10, 680 .

HART, R.G. \& MilleR, V.T. (1983) Cerebral infarction in young adults: a practical approach. Stroke, $14,110$.
IREY, N.S., MCAlLISTER, H.A. \& HENRY, J.R. (1978) Oral contra- ఏ ceptives and stroke in young women: a clinicopathologic correla- $-\bar{Z}$ tion. Neurology, 28, 1216.

KALBAG, R.M. \& Woolf, A.L. (1972) Thrombosis and thrombophlebitis of cerebral veins and dural sinuses. In: Handbook of Clinical Neurology, Vol. 12 (Eds. P.J. Vinken and G.W. Bruyn), p. $\overline{\overline{\bar{N}}}$ 442. North-Holland Publishing Company, Amsterdam.

LEE, S.H. \& RAO, K.C.V.G. (1983) Cranial Computed Tomography, p. 631. McGraw-Hill Book Company, New York.

Navarro, R., Berciano, J., Rebollo, M. \& Polo, J. (1978) Flebotrombosis intracraneal y anticonceptivos orales: presenta- $\vec{\nabla}$ ción de dos casos y revisión de la literatura. Revista Cltnica $\varrho$ Española, 148, 479.

Oster, P., Arab, L., Kohlmeir, M., Mordasini, R., SChellen- 0 BERG, B. \& SCHLIERF, G. (1982) Effects of estrogens and $\vec{\circ}$ progestogens on lipid metabolism. American Journal of Obstetrics and Gynecology, 142, 773.

RousseauX, P., Bernard, M.H., Scherpereel, B., Morel, M. \& GUYOT, J.F. (1977) Thrombose de sinus veineus intra-crâniens après prise d'estro-progestatifs. La Nouvelle Presse Médicale, 6, 2049.

Wallace, R., Hoover, J., Barket-Connor, E., Rifkind, B., HuminghaKe, D., MaCKenthum, D. \& Heiss, G. (1979) Altered plasma lipid and lipoprotein levels associated with oral contraceptive and oestrogen use. Lancet, ii, 111.

WAlsh, F.B., ClaRK, D.B., ThOMPSON, R.S. \& Nicholson, D.H. (1965) Oral contraceptives and neuro-ophthalmologic interest. $O$ Archives of Ophthalmology, 74, 628.

(Accepted 16 September 1983) 